\title{
Response to the international perspectives on the 2017 annual report of Department of Thoracic Surgery at Shanghai Chest Hospital
}

\author{
Wentao Fang \\ Department of Thoracic Surgery, Shanghai Chest Hospital, Jiao Tong University, Shanghai 200030, China \\ Correspondence to: Wentao Fang. Department of Thoracic Surgery, Shanghai Chest Hospital, Jiao Tong University, Shanghai 200030, China. \\ Email: vwtfang@hotmail.com. \\ Response to: Mathisen DJ. Commentary on the 2017 annual report of Shanghai Chest Hospital. Shanghai Chest 2018;2:19. \\ Patterson GA. Shanghai Chest Hospital—looking forward. Shanghai Chest 2018;2:61. \\ Leschber G. The annual report of shanghai chest hospital—a view from abroad. Shanghai Chest 2018;2:83.
}

Received: 06 September 2019; Accepted: 28 September 2019; Published: 30 September 2019.

doi: $10.21037 /$ shc. 2019.09 .03

View this article at: http://dx.doi.org/10.21037/shc.2019.09.03

Last year, the Department of Thoracic Surgery at the Shanghai Chest Hospital published its first annual report (1). Noticeably, it contained not only a remarkably large number of surgical cases and outstanding mortality rate after major thoracic procedures, but also details in evolution of thoracic surgery in general into each specific domains. Related research activities, publications, as well as clinical training programs, were also mentioned briefly. The report has gained international attention upon its publication in the journal of Shanghai Chest. Among feedbacks from thoracic surgeons worldwide, the comments by three eminent experts in the field, Dr. Douglas Mathisen (2), Alexander Patterson (3), and Guanda Leschber (4), were exceptionally incisive and helpful for further development of the Thoracic Surgery service at the Shanghai Chest Hospital.

The stunningly rapid increase in surgical volume, especially in lung cancer surgery, is most unlikely due to a 'Siphon' effect, i.e., centralization of thoracic surgery practice to top level institutions in China. Nor could be it contributed to concomitant increase in staff number in thoracic surgery service at the hospital. Similar trend of rapid increase in surgical volumes has been witnessed in other regions and at different levels of hospitals in China, although maybe not as remarkable as that at the Shanghai Chest Hospital (5). Two potential reasons for such change could be first, a growing use of CT screening for early stage lung cancers in the past decade nationwide, and second, a rapid popularization of minimally invasive surgery in management of early stage diseases across the country. The latter also helps explain the persistent decrease in surgical mortality throughout these years. With this advance in surgical technique and increasing attention to enhanced recovery programs, hospital stay has shortened to a great extent, without compromising management outcomes. Such changes have released significant potential in thoracic surgery service at top gear institutions, including the Shanghai Chest Hospital, as well as in other parts of China. This helps make high-standard care more readily accessible to the increasing need for thoracic surgery service from patients all over the country.

Meanwhile, this rapid surge in surgical volume, in addition to the large population in China, also provides unprecedented opportunities for clinical research and education. These were mentioned, but not in much details in the last report. In ultra-high volume centers, like the Shanghai Chest Hospital where up to a hundred major procedures are performed on the daily base, shorter period intensive clinical training may offer equivalent or even better education than months or years training at traditional high-volume centers. And more versatile approaches may be observed with dozens of surgeons operating simultaneously. In addition to routine clinical fellowships for domestic and international trainees, more than a dozen short-period immersion programs were hosted at the Shanghai Chest 
Hospital in the year 2018. And almost every weekend, there was a wet lab ongoing in minimally invasive thoracic procedures, benefiting hundreds of residents and fellows. These clinical education activities rely heavily on the joint effort by the hospital and the industries. Realizing the increasing demand for such training, the Shanghai Chest Hospital is going to set up its own simulation center and a wet lab inside the hospital to facilitate future training programs.

The ultra-high surgical volume is also a rich resource for clinical and translation-oriented researches. To make maximum use of it, current existing clinical database and biobank would need to be upgraded. Additional finance and manpower are desperately in need to support surgeons who already have an excessive clinical case load. Currently, clinical studies at the Shanghai Chest Hospital focus on innovative surgery and treatment modalities in thoracic oncology. These would be introduced more extensively in the upcoming report for the year 2018.

With persistent effort from the surgical staff at the Hospital and support from international societies, the 2018 annual report will definitely be more comprehensive and worthy of attention. By containing rich information on state-of-the-art thoracic surgery, it would be of great value in modeling future practice, research, and training in thoracic surgery, which is the continuing goal of the Shanghai Chest Hospital.

\section{Acknowledgments}

Funding: None.

\section{Footnote}

Provenance and Peer Review: This article was commissioned by the editorial office, Shanghai Chest. The article did not

doi: $10.21037 /$ shc.2019.09.03

Cite this article as: Fang W. Response to the international perspectives on the 2017 annual report of Department of Thoracic Surgery at Shanghai Chest Hospital. Shanghai Chest 2019;3:60. undergo external peer review.

Conflicts of Interest: The author has completed the ICMJE uniform disclosure form (available at http://dx.doi. org/10.21037/shc.2019.09.03). Wentao Fang serves as an unpaid Executive Editor-in-Chief of Shanghai Chest.

Ethical Statement: The author is accountable for all aspects of the work in ensuring that questions related to the accuracy or integrity of any part of the work are appropriately investigated and resolved.

Open Access Statement: This is an Open Access article distributed in accordance with the Creative Commons Attribution-NonCommercial-NoDerivs 4.0 International License (CC BY-NC-ND 4.0), which permits the noncommercial replication and distribution of the article with the strict proviso that no changes or edits are made and the original work is properly cited (including links to both the formal publication through the relevant DOI and the license). See: https://creativecommons.org/licenses/by-nc-nd/4.0/.

\section{References}

1. Yao F, Wang R, Guo X, et al. Annual report of Department of Thoracic Surgery at Shanghai Chest Hospital. Shanghai Chest 2018;2:18.

2. Mathisen DJ. Commentary on the 2017 annual report of Shanghai Chest Hospital. Shanghai Chest 2018;2:19.

3. Patterson GA. Shanghai Chest Hospital-looking forward. Shanghai Chest 2018;2:61.

4. Leschber G. The annual report of shanghai chest hospital—a view from abroad. Shanghai Chest 2018;2:83.

5. Sihoe ADL, Han B, Yang TY, et al. The Advent of Ultrahigh Volume Thoracic Surgical Centers in Shanghai. World J Surg 2017;41:2758-68. 